\title{
Assessment of an accelerometer system for detection of estrus and treatment with gonadotropin-releasing hormone at the time of insemination in lactating dairy cows
}

\author{
A. Valenza, ${ }^{*} \dagger{ }^{1}$ J. O. Giordano, ${ }^{* 1}$ G. Lopes Jr., ${ }^{* 1}$ L. Vincenti, $\neq$ M. C. Amundson, ${ }^{\star}$ and P. M. Fricke ${ }^{\star 2}$ \\ *Department of Dairy Science, University of Wisconsin, Madison 53706 \\ †Department of Animal Science, School of Agriculture, University of Turin, Turin, Italy 10095 \\ ¥Department of Animal Pathology, School of Veterinary Medicine, University of Turin, Turin, Italy 10095
}

\begin{abstract}
Two experiments were conducted to evaluate an accelerometer system (Heatime; SCR Engineers Ltd., Netanya, Israel) to manage reproduction in lactating dairy cows. In experiment 1, lactating Holstein cows (n $=112$ ) were fitted with an accelerometer system and were treated with $\mathrm{GnRH}$ followed $7 \mathrm{~d}$ later by $\mathrm{PGF}_{2 \alpha}$ to synchronize estrus. A total of 89 cows that had a follicle $>10 \mathrm{~mm}$ in diameter and a functional corpus luteum at the $\mathrm{PGF}_{2 \alpha}$ injection that regressed by $48 \mathrm{~h}$ after induction of luteolysis were included in the analysis. Overall, $71 \%$ of cows were detected in estrus by the accelerometer system and $95 \%$ of cows showing estrus ovulated within $7 \mathrm{~d}$ after induction of luteolysis. Of the cows not detected in estrus by the accelerometer system, 35\% ovulated within $7 \mathrm{~d}$ after induction of luteolysis. Duration of estrus activity (mean $\pm \mathrm{SD}$ ) was $16.1 \pm 4.7 \mathrm{~h}$ and was neither affected by parity nor milk production. Intervals (means $\pm \mathrm{SD}$ ) from induction of luteolysis, onset of activity, peak raw activity, and peak weighted activity to ovulation was $82.2 \pm 9.5,28.7 \pm 8.1,20.4$ \pm 7.8 , and $16.4 \pm 7.4 \mathrm{~h}$, respectively, and the interval from AI to ovulation was $7.9 \pm 8.7 \mathrm{~h}$, but ranged from -12 to $26 \mathrm{~h}$. In experiment 2, cows were assigned randomly to receive an intramuscular injection of $\mathrm{GnRH}$ at artificial insemination (AI) after detection of estrus by the accelerometer system or receive no treatment (control). Nine hundred seventy-nine AI services from 461 cows were analyzed. Treatment with $\mathrm{GnRH}$ at AI did not affect fertility at 35 or $65 \mathrm{~d}$ after AI, and no interaction was detected between treatment and season or treatment and AI number. Overall, two-thirds of the cows that were considered properly synchronized were inseminated based on the accelerometer system and ovulated after AI. The remaining cows either were not
\end{abstract}

Received April 18, 2012.

Accepted August 17, 2012.

${ }^{1}$ These authors contributed equally to this paper.

${ }^{2}$ Corresponding author: pmfricke@wisc.edu inseminated because they were not detected in estrus or would not have had a chance to conceive to AI because they failed to ovulate after estrus. Furthermore, mean time of AI in relation to ovulation determined by the accelerometer system was acceptable for most of the cows that displayed estrus; however, variability in the duration of estrus and timing of $\mathrm{AI}$ in relation to ovulation could lead to poor fertility in some cows. For lactating dairy cows detected in estrus by the accelerometer system, treatment with GnRH at the time of AI without reference to the onset of estrus did not increase fertility.

Key words: estrus detection, accelerometer, timing of ovulation, gonadotropin-releasing hormone at artificial insemination

\section{INTRODUCTION}

Despite the widespread adoption of hormonal synchronization protocols that allow for timed AI (TAI), detection of behavioral estrus continues to play an important role in the overall reproductive management program on most dairies in the United States (Caraviello et al., 2006; Miller et al., 2007). Estrus detection rates decreased from 50.9 and $59.6 \%$ in 1985 to 41.5 and $49.5 \%$ in 1999 for Southeastern US Holstein and Jersey dairy herds, respectively (Washburn et al., 2002), and are likely less than $50 \%$ on most US dairy farms (Senger, 1994). Some of the decrease in estrusdetection rates may be explained by attenuation of the duration of estrous behavior associated with increased milk production near the time of estrus (Lopez et al., 2004), few cows expressing standing estrus (Lyimo et al., 2000; Roelofs et al., 2005; Palmer et al., 2010), silent ovulations (Thatcher and Wilcox, 1973; Palmer et al., 2010; Ranasinghe et al., 2010), and reduced expression of estrous behavior of cows housed in confinement systems (Palmer et al., 2010). Whatever the cause, the poor efficiency of estrus detection not only increases time from calving to first AI but increases the average interval between AI services (Stevenson and Call, 
1983), thereby limiting the rate at which cows may become pregnant.

Because of the effect of AI service rate on reproductive performance and the problems associated with visual estrus detection on farms, many technologies have been developed to enhance estrus detection by providing constant surveillance of behavior, including rump-mounted devices and androgenized females (Gwazdauskas et al., 1990), pedometry (Kiddy, 1977; Maatje et al., 1997; Peralta et al., 2005; Roelofs et al., 2005), and radiotelemetry (Walker et al., 1996; Dransfield et al., 1998; Xu et al., 1998). New electronic systems that incorporate accelerometers as a means to associate increased physical activity with estrous behavior in cattle (Holman et al., 2011; Jónsson et al., 2011) have been developed and marketed to the dairy industry. Although a large body of literature exists on the accuracy and efficacy of using various technologies to predict ovulation and timing of AI in relation to ovulation in lactating dairy cows, no studies have investigated accelerometers for such purposes.

Treatment with GnRH at insemination continues to be used as a strategy to increase conception rates in dairy cattle after AI despite the large body of equivocal literature that exists on the efficacy of this treatment. Morgan and Lean (1993) conducted a meta-analysis of 40 experiments described in 27 published papers and concluded that although treatment at insemination with GnRH or GnRH analogs increased conception rates in dairy cattle, some variation in results were attributable to AI number at administration. One mechanism by which GnRH treatment at AI could potentially increase conception rate is by inducing ovulation in cows that would otherwise fail to ovulate after a spontaneous estrus. Ovulation failure after expression of estrus has been reported in dairy cattle (Sartori et al., 2004; López-Gatius et al., 2005a; Bloch et al., 2006) and contributes to poor fertility. Variability in the interval from the onset of estrus to ovulation resulting in delayed ovulation for some cows may also contribute to poor conception rates to AI (Bloch et al., 2006), and treatment with GnRH may reduce this variability, thereby increasing conception rate (Kaim et al., 2003). Despite the large body of literature published in this area, dairy farmers and veterinarians continue to inquire about the efficacy of $\mathrm{GnRH}$ treatment at the time of AI as a strategy to improve fertility.

Two experiments were conducted to assess the use of accelerometers for reproductive management of lactating dairy cows. The objectives of experiment 1 were to characterize (1) the percentage of cows detected in estrus based on activity determined by an accelerometer system and the percentage of cows ovulating after syn- chronization of the estrous cycle and (2) time intervals between the induction of luteal regression and estrus, AI, and ovulation in lactating dairy cows. Experiment 2 was conducted to evaluate the effect of GnRH treatment at the time of AI after detection of estrus based on an accelerometer system on fertility. Our hypothesis for experiment 2 was that cows treated with $\mathrm{GnRH}$ at the time of AI would have increased fertility compared with untreated cows.

\section{MATERIALS AND METHODS}

\section{Cows and Management for Experiments 1 and 2}

Lactating Holstein cows from a commercial dairy farm located in southwestern Wisconsin milking approximately 1,000 cows averaging approximately 41 $\mathrm{kg}$ of milk/d were used for these experiments. Experiment 1 was performed from August 2010 to June 2011, whereas experiment 2 was performed from June 2010 to January 2011. Cows were housed in freestall barns with ad libitum access to feed and water and were fed a TMR diet once daily that was formulated to meet or exceed NRC requirements (NRC, 2001) for highproducing lactating dairy cows. Cows were milked 3 times daily at approximately 8 -h intervals, and milk weights were recorded at each milking and stored in the on-farm dairy management software (DairyComp 305; Valley Agricultural Software, Tulare, CA). All cows received injections of bovine somatotropin (500 $\mathrm{mg}$, sometribove zinc; Elanco Animal Health Co., Indianapolis, IN) beginning 57 to $70 \mathrm{~d}$ postpartum and continuing every $14 \mathrm{~d}$ until dry-off. All procedures were approved by the Animal Care and Use Committee for the College of Agriculture and Life Sciences of the University of Wisconsin-Madison.

\section{Experiment 1: Synchronization of Estrus and Evaluation of Physiologic Parameters}

One hundred twelve cows (47 primiparous and 65 multiparous) were enrolled in experiment 1. Each week, cohorts of 10 to 15 cows from 46 to 52 DIM were evaluated by transrectal ultrasonography using a portable scanner fitted with a $7.5-\mathrm{MHz}$ linear-array transducer (Easi-Scan; BCF Technology Ltd., Livingston, UK) to determine uterine health and record ovarian structures. Cows without signs of uterine disease and at least 1 follicle $\geq 10 \mathrm{~mm}$ in diameter received an intramuscular injection of $\mathrm{GnRH}(100 \mu \mathrm{g}$ of gonadorelin diacetate tetrahydrate, Fertagyl; Intervet Animal Health, Millsboro, DE) followed by an intramuscular injection of $\mathrm{PGF}_{2 \alpha}$ (25 $\mathrm{mg}$ of dinoprost tromethamine, Lutalyse; Pfizer 


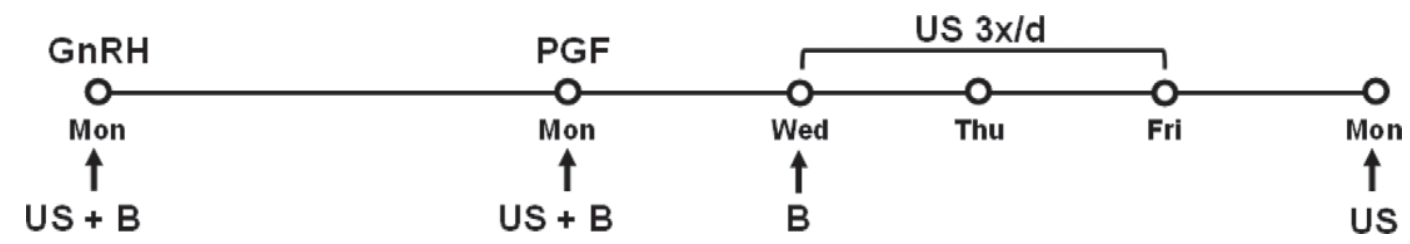

Figure 1. Schematic diagram of activities for experiment 1. Cows $(\mathrm{n}=112)$ from 46 to $52 \mathrm{~d}$ postpartum received a hormonal protocol to synchronize estrus using intramuscular injections of $\mathrm{GnRH}(100 \mu \mathrm{g})$ and $\mathrm{PGF}_{2 \alpha}(25 \mathrm{mg})$. Transrectal ultrasonography (US) was used to assess ovarian structures during the protocol and time of ovulation after induction of luteolysis, and blood samples (B) were collected to assess serum progesterone concentration. After eliminating 23 cows that failed to synchronize to the protocol, 89 cows were included in the analysis.

Animal Health, New York, NY) 7 d later to synchronize estrus (Figure 1). Transrectal ultrasonography was performed at the time of the $\mathrm{PGF}_{2 \alpha}$ injection for subsequent determination of ovulatory response to $\mathrm{GnRH}$ treatment. Diameter of ovarian structures was estimated and recorded using on-screen background gridlines comprising squares with $10-\mathrm{mm}$ sides in the portable scanner. Ovulation was defined as the presence of a follicle $\geq 10 \mathrm{~mm}$ at the initial ultrasound examination at the time of the GnRH injection and the presence of a new corpus luteum (CL) in the same location at the subsequent ultrasound examination at the time of the $\mathrm{PGF}_{2 \alpha}$ injection. Thereafter, ovarian ultrasonography was performed $48 \mathrm{~h}$ after the $\mathrm{PGF}_{2 \alpha}$ injection and then every $8 \mathrm{~h}$ until ovulation occurred or until $96 \mathrm{~h}$, whichever occurred first. Cows failing to ovulate by $96 \mathrm{~h}$ of the $\mathrm{PGF}_{2 \alpha}$ injection were reexamined $3 \mathrm{~d}$ later (i.e., $7 \mathrm{~d}$ after the $\mathrm{PGF}_{2 \alpha}$ injection) to determine whether ovulation had occurred.

\section{Detection of Estrus and AI}

At approximately $14 \mathrm{~d}$ after calving, all cows were fitted with an accelerometer (Heatime; SCR Engineers Ltd., Netanya, Israel) attached to a neck collar and an electronic identification (ID) tag. After each milking, data collected by the accelerometer was read by a transceiver unit placed in an archway at the milking parlor exit and then transferred to the accelerometer herd management software (Data Flow; Micro Dairy Logic, Amarillo, TX) installed on the on-farm computer. All settings of the herd management software were based on those being used by the farm at the time of the experiment, and these settings were not changed throughout the course of the 2 experiments.

The accelerometer system continuously monitored individual cow activity and recorded average activity for 2 -h time periods throughout experiment 1 . The raw activity of individual cows was plotted as a bar graph where each bar represented a 2 -h block of time (Figure 2). Using a mathematical algorithm, a weighted activity index was calculated by the software that expressed the momentary deviation of the activity from the average activity in the same time period during the past 7 d (Bar, 2010), and weighted activity was represented on the activity report by a solid line (Figure 2). Graphs were generated for individual cows, and data regarding the timing of the onset of activity, peak raw and weighted activity, intensity of raw and weighted activity, and the duration of activity were recorded for each estrus event. Onset of activity was defined as the time at which the first bar of raw activity of an estrus event was identified. Time to peak raw activity was defined as the time at which the maximum value for raw activity was recorded. Time of peak weighted activity was defined as the time at which the maximum height of the weighted activity was observed. Raw and weighted peak intensity was recorded as the activity value recorded for the time of maximum raw and weighted activity. Finally, duration of activity was defined as the time interval between the beginning and end of activity for an estrus event.

Pressure-activated Heatmount detectors (Kamar Heatmount Detectors; Kamar Inc., Steamboat Springs, $\mathrm{CO}$ ) were affixed midline to the rump between the tail head and the tuber coxae (hook bones) for all cows in experiment 1 as an additional means for detecting estrus. Heatmount detectors were affixed at the time of the $\mathrm{PGF}_{2 \alpha}$ injection of the synchronization protocol and were assessed $48 \mathrm{~h}$ after the $\mathrm{PGF}_{2 \alpha}$ injection, at each milking (i.e., every $8 \mathrm{~h}$ ) from $48 \mathrm{~h}$ after the $\mathrm{PGF}_{2 \alpha}$ injection until activation or until $96 \mathrm{~h}$ (whichever occurred first) and $7 \mathrm{~d}$ after the $\mathrm{PGF}_{2 \alpha}$ injection. The condition of the Heatmount detector was recorded as either activated (red) or nonactivated (white). No cows lost Heatmount detectors during the course of the experiment.

Twice daily (a.m. and p.m.), a list of cows determined by the accelerometer system to be eligible for insemination was generated, and cows appearing on the list generated by the accelerometer system were inseminated. Thus, inseminations were conducted twice daily (a.m. and p.m.) by 2 herd personnel with each cow receiving a single insemination based on activity. 


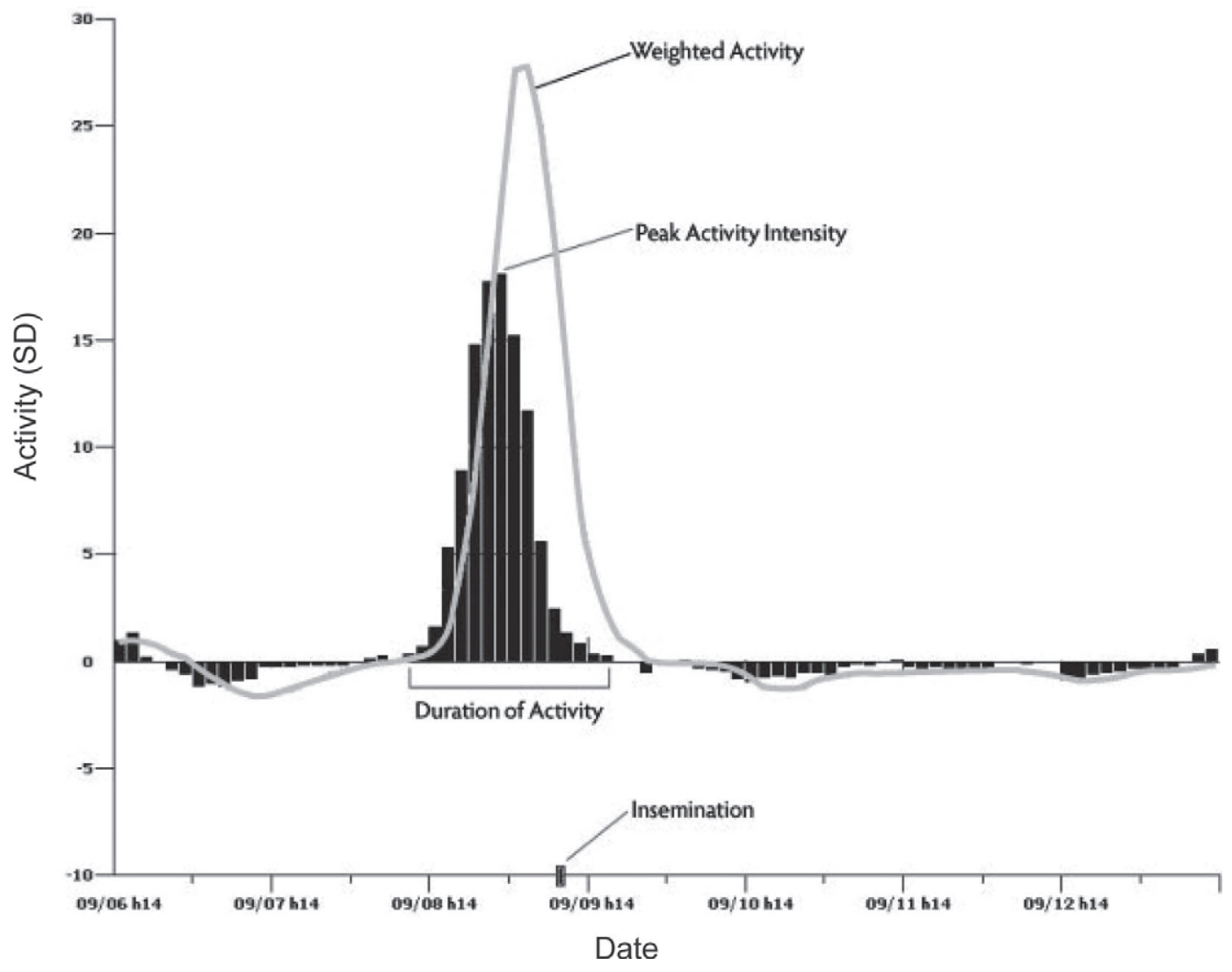

Figure 2. A representative graph of an activity report for a cow in experiment 1 generated by the Data Flow software of the accelerometer system (Heatime; SCR Engineers Ltd., Netanya, Israel). The accelerometer system continuously monitored individual cow activity and recorded average activity for 2-h time periods (bars) throughout the experiment. Activity data were analyzed by the system software using an algorithm that created a weighted activity value represented by a line from which timing of insemination was determined.

\section{Blood Collection and Progesterone Analysis}

Blood samples for analysis of serum progesterone (P4) concentrations were collected via puncture of the median caudal vein or artery into evacuated tubes (Vacutainer; BD, Franklin Lakes, NJ). Blood samples ( $~ 8$ $\mathrm{mL}$ ) were centrifuged $(1,935 \times g$ for $20 \mathrm{~min})$, and serum was collected and stored at $-20^{\circ} \mathrm{C}$ until assayed for P4 concentrations using a solid-phase, no-extraction RIA (Coat-a-count; Diagnostic Products Corp., Los Angeles, CA). Intra- and interassay coefficients of variation were 1.6 and $7.6 \%$, respectively.

Blood samples were collected at the time of the GnRH injection, the $\mathrm{PGF}_{2 \alpha}$ injection, and $48 \mathrm{~h}$ after the $\mathrm{PGF}_{2 \alpha}$ injection of the synchronization protocol (Figure 1). Blood samples collected at the time of the GnRH and $\mathrm{PGF}_{2 \alpha}$ injections were used in addition to transrectal ultrasonography to determine the ovulatory response to GnRH. Samples collected at the time of the $\mathrm{PGF}_{2 \alpha}$ injection also were used to determine the presence of a functional CL. Blood samples collected $48 \mathrm{~h}$ after the $\mathrm{PGF}_{2 \alpha}$ injection were used to determine luteal regression in response to $\mathrm{PGF}_{2 \alpha}$ treatment. Cows were considered to have undergone luteal regression when $\mathrm{P} 4$ concentration in the sample collected at the time of the $\mathrm{PGF}_{2 \alpha}$ injection was $\geq 1 \mathrm{ng} / \mathrm{mL}$ and $\leq 1 \mathrm{ng} / \mathrm{mL}$ in the sample collected $48 \mathrm{~h}$ after the $\mathrm{PGF}_{2 \alpha}$ injection.

\section{Experiment 2}

Cows were eligible for AI after detection of estrus based on the accelerometer system when more than 50 DIM (voluntary waiting period). Cows were randomized to 2 treatments based on their ear tag ID numbers. Cows with even ID numbers received an intramuscular injection of $\mathrm{GnRH}(100 \mu \mathrm{g}$ of gonadorelin diacetate tetrahydrate, Fertagyl; Intervet Animal Health) at the time of AI, whereas cows with odd ID numbers remained untreated and served as controls. Nine hundred seventy-nine AI services from 461 cows (177 primiparous and 284 multiparous cows) were included in the analysis. Of the 979 AI services, 445 AI services were included in the GnRH treatment and 534 AI services were included in the control. Artificial insemination was 
performed twice daily based on activity detected by the accelerometer system as described for experiment 1 .

Official temperature data (Midwestern Climate Center, Champaign, IL) reported at a research station located $5 \mathrm{~km}$ from the farm (Lancaster, WI; latitude: $42.8475^{\circ} \mathrm{N}$, longitude: $90.7106^{\circ} \mathrm{W}$ ) was collected retrospectively. The high temperature on the day of AI was used for the analysis of season on pregnancies per AI ( $\mathbf{P} / \mathbf{A I})$. A daily high temperature $>20^{\circ} \mathrm{C}$ on the day of AI was classified as having occurred during the warm season, whereas a daily high temperature $\leq 20^{\circ} \mathrm{C}$ on the day of AI was classified as having occurred during the cool season.

\section{Pregnancy Diagnosis}

Pregnancy diagnosis for the evaluation of $\mathrm{P} / \mathrm{AI}$ and pregnancy loss in experiment 2 was performed by the herd veterinarian $35 \pm 3$ and $65 \pm 3 \mathrm{~d}$ after AI using transrectal ultrasonography (Aloka $500 \mathrm{~V}$ with a 5.0$\mathrm{MHz}$ linear array transducer; Corometrics Medical Systems Inc., Wallingford, CT). Cows diagnosed pregnant $35 \pm 3 \mathrm{~d}$ after $\mathrm{AI}$ and subsequently diagnosed nonpregnant at $65 \pm 3 \mathrm{~d}$ were considered to have undergone pregnancy loss.

\section{Data Management and Statistical Analyses}

Experiment 1. Data from 23 of the 112 cows enrolled in the experiment were excluded from the data set for the following reasons: 2 cows were anovular (no CL detected and $\mathrm{P} 4$ concentrations $<1.0 \mathrm{ng} / \mathrm{mL}$ at the time of the GnRH and $\mathrm{PGF}_{2 \alpha}$ treatment of the synchronization protocol), 9 cows with CL had luteal regression before the $\mathrm{PGF}_{2 \alpha}$ injection, 4 cows were detected in estrus by the accelerometer system and were inseminated during the synchronization protocol (i.e., between the $\mathrm{GnRH}$ and $\mathrm{PGF}_{2 \alpha}$ injections), and 8 cows did not undergo complete luteal regression by 48 $\mathrm{h}$ after the $\mathrm{PGF}_{2 \alpha}$ injection. After elimination of data from these 23 cows, data from a total of 89 cows were included in the analysis.

Analysis of the percentage of cows in specific groups (estrus vs. no estrus, and estrus-ovulation, estrus-no ovulation, no estrus-ovulation, and no estrus-no ovulation) was determined using PROC FREQ of SAS 9.2 (version 9.2; SAS Institute Inc., Cary, NC), whereas differences in the percentage of cows detected in estrus by the accelerometer system and the Heatmount detectors were determined by logistic regression using the events over trials option of PROC LOGISTIC of SAS. Analysis of the time intervals for the specific events under consideration (induction of luteolysis to onset of estrus activity, peak raw activity, peak weighted activ- ity, and ovulation, onset of activity, peak raw activity, and peak weighted activity to ovulation, induction of luteolysis to AI, onset of estrus activity to ovulation, and AI to ovulation) was performed using PROC MEANS of SAS.

Effect of parity on duration of estrus activity as determined by the accelerometer system was analyzed by ANOVA using PROC GLM of SAS with a model that contained parity (primiparous vs. multiparous) as a categorical explanatory variable and milk production as a covariate. The relationship between duration of estrus and the onset of activity to ovulation interval and between milk production and peak intensity for weighted activity was determined by simple linear regression using PROC GLM of SAS. Mean milk production during the 7 consecutive days immediately preceding estrus but not including the day of estrus was used for these analyses.

Experiment 2. The experimental design was a complete randomized block design with parity (primiparous vs. multiparous) as the blocking factor. Analyses of the binary response variables $\mathrm{P} / \mathrm{AI}$ and pregnancy loss were performed by logistic regression using the GLIMMIX procedure of SAS. For $\mathrm{P} / \mathrm{AI}$ at $35 \pm 3$ and 65 $\pm 3 \mathrm{~d}$ after TAI, the initial model contained as fixed effects the following categorical explanatory variables: treatment (GnRH vs. control), parity (primiparous vs. multiparous), AI number $(2,3,4,5$, or $\geq 6$ ), and AI technician (1 vs. 2) as well as the interaction between all these variables. Given that the experimental unit was the AI service, all initial models contained both fixed and random effects. Fixed effects included in the initial models were the classification variables: treatment, parity, AI service number, AI technician, and their interactions, whereas cow was included as a random effect to account for any potential variation due to cows receiving multiple AI services.

Based on a covariance parameter estimate test, the random effect of cow was removed from the model so that all final models contained only fixed effects. The covariance parameter test using the ZeroG option for the GLIMMIX procedure was used to evaluate if the matrix containing random effects could be reduced to zero. A covariance parameter test based on the residual pseudo-likelihood was run and a nonsignificant chisquared $P$-value indicated that random effects could be eliminated from the model (SAS documentation for GLIMMIX, SAS 9.2). After removing random effects, selection of the fixed effects model that best fit the data for each variable of interest was performed by finding the model with the lowest value for the Akaike information criterion using a backward elimination procedure that removed all variables with $P>0.10$ from the model. The final model for analyzing $\mathrm{P} / \mathrm{AI} 35 \pm 3$ and 65 
$\pm 3 \mathrm{~d}$ after $\mathrm{AI}$ contained the fixed effects of treatment, parity, season, and the parity by season interaction. Treatment was forced to remain in all models.

For analysis of pregnancy loss, the same categorical variables (except AI technician) and interactions used for P/AI were used to obtain the models for pregnancy loss from $35 \pm 3$ to $65 \pm 3 \mathrm{~d}$ after AI. Procedures and criteria used for model selection were similar to those used for P/AI. The final model included treatment and parity. Both variables were forced in the model.

A significant difference between the levels of a classification variable was considered when $P<0.05$, whereas differences between $P \geq 0.05$ and $P \leq 0.10$ were considered a statistical tendency. Data included in the text are presented as arithmetic means $( \pm \mathrm{SD})$ and range when appropriate obtained using PROC MEANS of SAS or percentages obtained with PROC FREQ of SAS.

\section{RESULTS AND DISCUSSION}

\section{Experiment 1}

Estrus Activity and Ovulation. The hormonal protocol consisting of GnRH followed $7 \mathrm{~d}$ later by $\mathrm{PGF}_{2 \alpha}$ used to synchronize estrus in experiment 1 effectively synchronized the estrous cycles of $79 \%(89 / 112)$ of the cows enrolled that had a functional CL capable of responding to the $\mathrm{PGF}_{2 \alpha}$ injection and a follicle $\geq 10$ $\mathrm{mm}$ at the time of induction of luteolysis. Mean P4 concentration at the time of $\mathrm{GnRH}$ treatment was 2.4 $\pm 2.3 \mathrm{ng} / \mathrm{mL}$ (range 0.0 to 8.5 ), $4.4 \pm 2.4 \mathrm{ng} / \mathrm{mL}$ (range 1.0 to 11.2$)$ at the time of $\mathrm{PGF}_{2 \alpha}$ treatment, and $0.2 \pm$ $0.1 \mathrm{ng} / \mathrm{mL}$ (range 0.0 to 0.7 ) $48 \mathrm{~h}$ after $\mathrm{PGF}_{2 \alpha}$ treatment. Ovulatory response to $\mathrm{GnRH}$ treatment was $74 \%$ $(66 / 89)$. Because only synchronized cows were included in the analyses, we expected the majority of cows to be detected in estrus and ovulate within $7 \mathrm{~d}$ after the $\mathrm{PGF}_{2 \alpha}$ injection. We chose to synchronize the estrous cycle of cows for experiment 1 so that groups of cows would be available for data collection on specific days of the week at the collaborating dairy. No physiological or behavioral differences have been reported between spontaneous and hormonally induced estruses in lactating dairy cows (Walker et al., 1996; Roelofs et al., 2005; Bloch et al., 2006).

The percentage of cows with estrus events detected by the accelerometer system and Heatmount detectors and the distribution of cows by occurrence of estrus and ovulation are presented in Table 1. Overall, the percentage of cows detected in estrus did not differ statistically $(P=0.52)$ between the accelerometer system and the Heatmount detectors (71 vs. $66 \%$, re-
Table 1. Percentage of cows defined to be in estrus, and distribution of cows by estrous activity and ovulation based on use of an accelerometer system or Heatmount detectors

\begin{tabular}{|c|c|c|}
\hline Item & $\begin{array}{c}\text { Accelerometer system } \\
{[\% \text { (no. of cows }} \\
\text { detected/total } \\
\text { no. of cows) }]\end{array}$ & $\begin{array}{c}\text { Heatmount detectors } \\
{[\% \text { (no. of cows }} \\
\text { detected } / \text { total } \\
\text { no. of cows) }]\end{array}$ \\
\hline Estrus $^{3}$ & $71(63 / 89)$ & $66(59 / 89)$ \\
\hline Ovulation & $95(60 / 63)$ & $93(55 / 59)$ \\
\hline No ovulation & $5(3 / 63)$ & $7(4 / 59)$ \\
\hline No estrus & $29(26 / 89)$ & $34(30 / 89)$ \\
\hline Ovulation & $35(9 / 26)$ & $47(14 / 30)$ \\
\hline No ovulation & $65(17 / 26)$ & $53(16 / 30)$ \\
\hline
\end{tabular}

${ }^{1}$ Heatime (SCR Engineers Ltd., Netanya, Israel).

${ }^{2}$ Kamar Heatmount detectors (Kamar Inc., Steamboat Springs, CO).

${ }^{3}$ The percentage of cows detected in estrus within $7 \mathrm{~d}$ after treatment with $\mathrm{GnRH}$ followed $7 \mathrm{~d}$ later by $\mathrm{PGF}_{2 \alpha}$ to synchronize estrus in this experiment did not differ $(P=0.52)$ between the accelerometer system and the Heatmount detectors.

spectively). Throughout the study period, $78 \%(69 / 89)$ of cows ovulated by $7 \mathrm{~d}$ after induction of luteolysis. Of the cows that ovulated, $59 \%(41 / 69)$ ovulated within 96 h, whereas $41 \%(28 / 69)$ ovulated from 96 to $168 \mathrm{~h}$ (4 to $7 \mathrm{~d}$ ) after induction of luteolysis. Overall, $71 \%$ of cows were detected in estrus by the accelerometer system, and $95 \%$ of cows showing estrus ovulated within $7 \mathrm{~d}$ of induction of luteolysis. Of the cows not detected in estrus by the accelerometer system, $35 \%$ ovulated within $7 \mathrm{~d}$ of induction of luteolysis. The overall percentage of cows detected in estrus in this experiment is within the range reported for lactating dairy cows synchronized using a G-P protocol followed by visual observation of estrus (Stevenson et al., 1999).

Duration of estrus activity for cows detected in estrus by the accelerometer system $(16.1 \pm 4.7 \mathrm{~h}$, range $=$ 4.0 to 28.0 ; Figure 3$)$ was not affected $(P=0.74)$ by parity (16.4 vs. $17.2 \mathrm{~h}$ for primiparous and multiparous, respectively) or milk production near the time of estrus $(P=0.51)$. Duration of estrus observed in the present experiment is comparable to the mean duration (13.4 h) reported for cows monitored for estrus by visual observation of both primary (standing to be mounted) and multiple secondary signs of estrous behavior (Roelofs et al., 2004). Conversely, duration of estrus activity observed in the present experiment is considerably longer than the mean duration of estrus based on the interval between the first and last standing event of estrus detected using an electronic pressure-sensing system (Dransfield et al., 1998; Xu et al., 1998). Discrepancies between duration of estrus based on activity or visual observation with that recorded based on standing events are possibly due to the uncoupling of expression of secondary signs of estrus behavior and standing estrus. Indeed, Sveberg et al., (2011) reported 


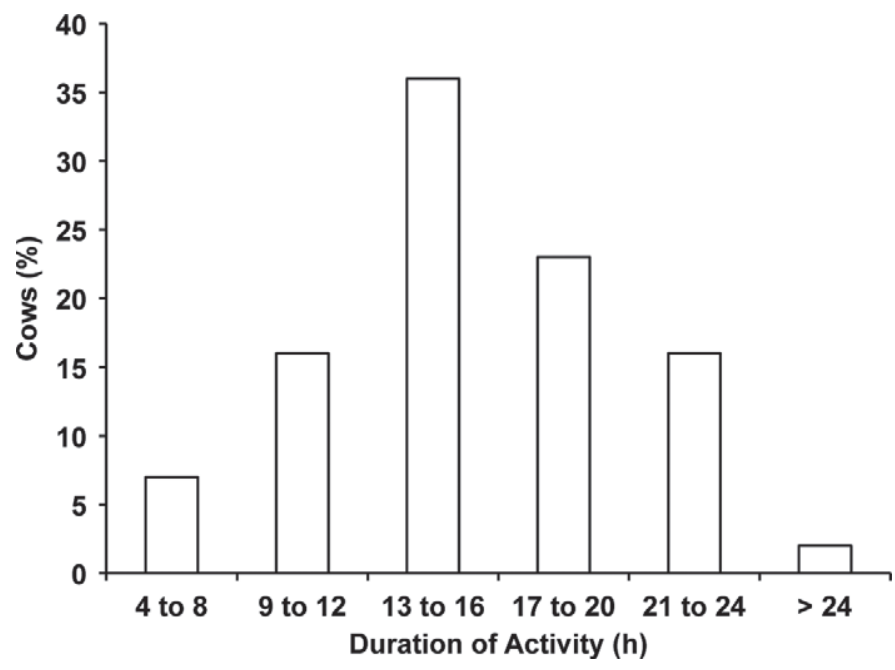

Figure 3. Percentage distribution of cows based on duration of activity associated with estrus for cows detected in estrus $(n=61$; no duration data was available for 2 cows of the 63 cows detected in estrus) by the accelerometer system (Heatime; SCR Engineers Ltd., Netanya, Israel) within $7 \mathrm{~d}$ after synchronization of estrus (experiment 1). Estrus was synchronized using an intramuscular injection of $\mathrm{GnRH}$ $(100 \mu \mathrm{g})$ and induction of luteolysis using $\mathrm{PGF}_{2 \alpha}(25 \mathrm{mg}) 7 \mathrm{~d}$ later.

that secondary signs of estrous behavior, which can certainly be detected by visual observation or increased activity, increased significantly within 1 to $3 \mathrm{~h}$ before the initiation of standing estrus in lactating dairy cows.

Because activity was only monitored during the $7-d$ period after the $\mathrm{PGF}_{2 \alpha}$ injection of the synchronization protocol, it is possible that some cows would have showed estrus after data collection concluded. It was not possible to determine when cows failing to ovulate during the 7-d period after the $\mathrm{PGF}_{2 \alpha}$ injection ovulated because these cows received an Ovsynch protocol and TAI at the end of the 7-d period. Nevertheless, we did not expect that approximately $30 \%$ of cows would fail to show estrus within $7 \mathrm{~d}$ after the $\mathrm{PGF}_{2 \alpha}$ injection because a follicle $>10 \mathrm{~mm}$ was present in all cows at the time of the $\mathrm{PGF}_{2 \alpha}$ injection, and all cows had luteal regression in $48 \mathrm{~h}$ after $\mathrm{PGF}_{2 \alpha}$ treatment. In another study in which cows received 2 sequential $\mathrm{PGF}_{2 \alpha}$ injections at 35 and 49 DIM, only $67.9 \%$ of cows determined to be cycling by 49 DIM were detected in estrus and inseminated after the second $\mathrm{PGF}_{2 \alpha}$ injection, leading the authors to conclude that issues other than cyclicity status affected efficiency and accuracy of estrus detection (Chebel and Santos, 2010). The percentage of cows that failed to ovulate within the group of cows not detected in estrus was $65 \%(17 / 26)$ for the accelerometer system and 53\% (16/30) for Heatmount detectors, suggesting that estrus did not occur in these cows. The remaining 35 and $47 \%$ of ovulations in cows not detected in estrus may have been silent ovulations (ovulation without estrus), a phenomenon described in lactating dairy cows especially during the early postpartum period (Thatcher and Wilcox, 1973; Palmer et al., 2010; Ranasinghe et al., 2010).

In the present experiment, $5 \%$ (3/63 for the accelerometer system) or $7 \%$ (4/59 for Heatmount detectors) of cows detected in estrus failed to ovulate within $7 \mathrm{~d}$ after induction of luteolysis. The overall rate of ovulation failure in lactating dairy cows that showed estrus behavior was $6.5 \%$ and was greater during the warm (12.4\%) than during the cool (3.4\%) season (LópezGatius et al., 2005a). This rate of ovulation failure represents a small percentage of the population of cows in this experiment and may have occurred because of failure in the mechanism triggering ovulation (i.e., no LH surge or insufficient LH secretion) or a lack of response by the dominant follicle to the LH surge.

Timing of Events After Induction of Luteolysis for Cows Detected in Estrus with the Accelerometer System. Time intervals for the events under consideration for all cows that ovulated by 7 $\mathrm{d}$ after induction of luteolysis with $\mathrm{PGF}_{2 \alpha}$ and those cows ovulating by $96 \mathrm{~h}$ after induction of luteolysis for cows detected in estrus by the accelerometer system are presented in Tables 2 and 3. Interval between induction of luteolysis with $\mathrm{PGF}_{2 \alpha}$ and the onset of activity observed in the present experiment is within the range reported for cows synchronized using the same G-P protocol and twice daily visual observation of estrus after synchronization (Stevenson et al., 1999).

In the present experiment in which ovarian ultrasonography was performed every $8 \mathrm{~h}$, the mean interval from onset of activity to ovulation of $28.7 \mathrm{~h}$ agrees with the reported mean interval of $27.6 \mathrm{~h}$ from the onset of standing activity to ovulation in lactating dairy cows detected with an electronic pressure-sensing system (Walker et al., 1996) or visual observation of estrus (Kaim et al., 2003; Roelofs et al., 2004; Bloch et al., 2006). Furthermore, the interval between the onset of activity to ovulation based on an accelerometer system in the present experiment is similar to the reported interval between an increase in walking activity measured with pedometers and ovulation $(\sim 29$ to $30 \mathrm{~h})$ in lactating dairy cows (Roelofs et al., 2005; Roelofs et al., 2006). The wide degree of variation among cows observed for the interval from onset of activity to ovulation in this experiment (Figure 4) also agrees with that reported by others (Walker et al., 1996; Roelofs et al., 2005). This variability would contribute to the variation observed in the AI to ovulation interval observed in this experiment (Figure 5) and is a cause for concern because of potential errors in the timing of AI in relation to ovulation. 
Table 2. Interval from induction of luteolysis with $\mathrm{PGF}_{2 \alpha}$ to onset of activity, peak of raw and weighted activity, and AI, and from the onset of activity to $\mathrm{AI}$ for cows ${ }^{1}$ that ovulated within $7 \mathrm{~d}$ after induction of luteolysis and were detected in estrus based on activity determined by an accelerometer system ${ }^{2}$

\begin{tabular}{|c|c|c|c|c|}
\hline Interval & $\mathrm{n}$ & Mean $\pm \mathrm{SD}$ & Minimum & Maximum \\
\hline Induction of luteolysis to peak raw activity (h) & 59 & $71.2 \pm 17.2$ & 42.0 & 130.0 \\
\hline Induction of luteolysis to peak weighted activity (h) & 60 & $74.0 \pm 17.1$ & 40.0 & 136.0 \\
\hline Onset of activity to AI (h) & 59 & $20.8 \pm 7.0$ & 11.0 & 47.0 \\
\hline
\end{tabular}

${ }^{1}$ One cow was not included in these intervals because no data were available from the software system for the calculation of specific intervals.

${ }^{2}$ Heatime (SCR Engineers Ltd., Netanya, Israel).

The shorter mean time interval from peak raw activity $(20.4 \mathrm{~h})$ and peak weighted activity $(16.5 \mathrm{~h})$ to ovulation suggests that both of these events occur after the onset of standing activity is initiated. Considering an average duration of estrus activity in this experiment of $16.8 \mathrm{~h}$ for cows that ovulated within $96 \mathrm{~h}$ of the $\mathrm{PGF}_{2 \alpha}$ injection, both peak raw and weighted activity as determined by the accelerometer system are events close to the end of estrus in lactating dairy cows. In agreement with results from Experiment 1, Roelofs et al. (2004) reported that the time interval from the end of estrus to ovulation was $16.7 \mathrm{~h}$ when estrus was determined by visual observation whereas in another experiment in which estrus was determined by pedometer activity the interval from the end of estrus to ovulation was 19.4 h (Roelofs et al., 2005). Further research is needed to determine the exact relationship between the various measures of activity and standing estrus in lactating dairy cows.

As a result of the short lifespan of the oocyte in cattle (Hunter, 2003), the interval from AI to ovulation is critical for optimizing fertility in lactating dairy cows inseminated after detection of estrus. Mean interval from AI to ovulation of $7.9 \mathrm{~h}$ observed in the present experiment in which inseminations were conducted twice daily (a.m. and p.m.) after detection of estrus based on the accelerometer system is appropriate because it allows for the 6 to $8 \mathrm{~h}$ required for the sustained phase of sperm transport to the site of fertilization and sperm capacitation (Hunter and Wilmut, 1983; Wilmut and
Hunter, 1984; Hawk, 1987). In the present experiment, however, the degree of variation in the AI to ovulation interval (Figure 5) is a major concern. Overall, 21\% of cows received AI between 0 to $12 \mathrm{~h}$ after ovulation, a timing associated with low fertilization rates and embryo quality in lactating dairy cows (Roelofs et al., 2006) possibly due to aging of the oocyte during the period required for sperm transport and capacitation. By contrast, only 1 cow was inseminated more than 24 $\mathrm{h}$ before ovulation, a period that results in high fertilization rates but low embryo quality possibly due to aging of the spermatozoa (Roelofs et al., 2006). Based on these data, it may be helpful to reduce the variation in the AI to ovulation interval so that more cows are inseminated at the optimal time in relation to ovulation. Alternatively, cows could be inseminated a few hours earlier to reduce the probability of inseminating cows after or near the time of ovulation.

Relationship Between Measures of Activity with Ovulation Time and Milk Production. A positive linear association $\left(P<0.01 ; \mathrm{R}^{2}=33 \%\right)$ between duration of activity and the interval between the onset of activity and ovulation was observed in the present experiment. As duration of activity increased, the interval from the onset of activity to ovulation increased (Figure 6). Walker et al. (1996) reported a similar relationship between the duration of estrus defined as the time elapsed from the first to the last standing event of estrus and the interval from the onset of estrus to ovulation in lactating dairy cows. Based

Table 3. Interval from induction of luteolysis with $\mathrm{PGF}_{2}$ to ovulation, onset of activity to ovulation, peak of raw and weighted activity to ovulation, and AI to ovulation for cows $(\mathrm{n}=38)$ that ovulated within $96 \mathrm{~h}$ after induction of luteolysis and were detected in estrus based on activity determined by an accelerometer system ${ }^{1}$

\begin{tabular}{lccc}
\hline Interval & Mean $\pm \mathrm{SD}$ & Minimum & Maximum \\
\hline Induction of luteolysis to ovulation $(\mathrm{h})$ & $82.2 \pm 9.5$ & 60.0 & 92.0 \\
Onset of activity to ovulation (h) & $28.7 \pm 8.1$ & 6.0 & 42.0 \\
Peak raw activity to ovulation (h) & $20.4 \pm 7.8$ & 0.0 & 32.0 \\
Peak weighted activity to ovulation (h) & $16.4 \pm 7.4$ & 0.0 & 34.0 \\
AI to ovulation (h) & $7.9 \pm 8.7$ & -12.0 & 26.0 \\
\hline
\end{tabular}

${ }^{1}$ Heatime (SCR Engineers Ltd., Netanya, Israel). 


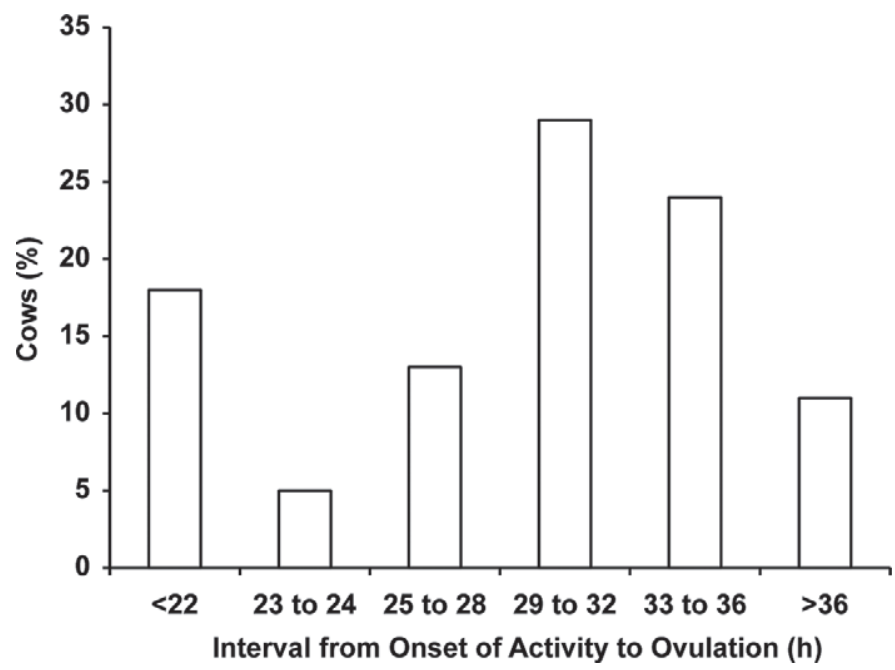

Figure 4. Percentage distribution of cows $(\mathrm{n}=38)$ based on interval from onset of activity detected using the accelerometer system (Heatime; SCR Engineers Ltd., Netanya, Israel) to ovulation (experiment 1). Estrus was synchronized using an intramuscular injection of GnRH $(100 \mu \mathrm{g})$ and induction of luteolysis using $\mathrm{PGF}_{2 \alpha}(25 \mathrm{mg}) 7 \mathrm{~d}$ later.

on these observations, Walker et al. (1996) suggested that during the early stages of estrus, the concentration of circulating estradiol may have been sufficient to induce estrous behavior but inadequate to trigger the

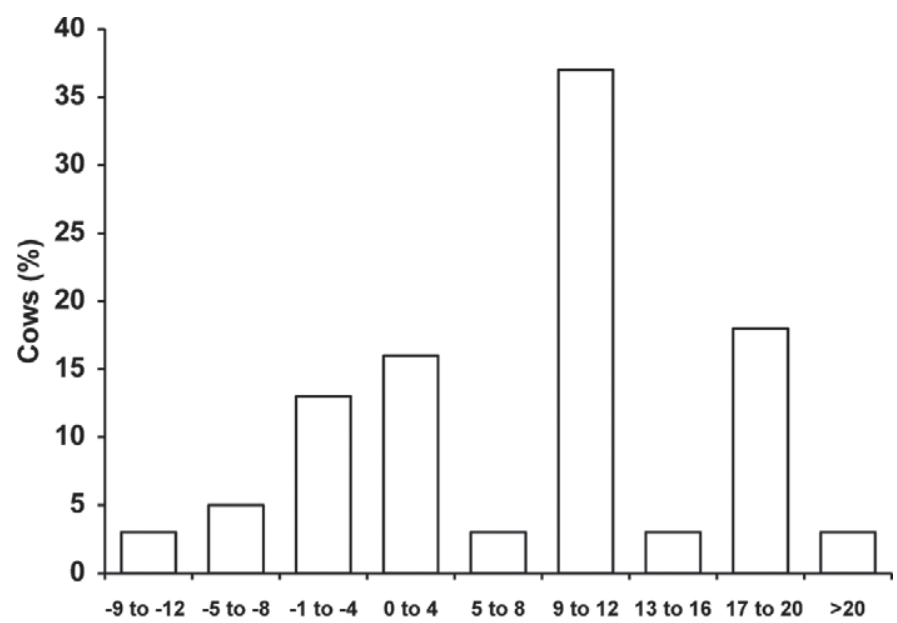

Interval from Al to Ovulation (h)

Figure 5. Percentage distribution of cows $(\mathrm{n}=38)$ based on the interval from AI to ovulation. Artificial insemination was conducted twice daily based on detected estrus defined by the accelerometer system (Heatime; SCR Engineers Ltd., Netanya, Israel; experiment 1). Ovulation was determined using transrectal ultrasonography conducted every $8 \mathrm{~h}$ from 48 to $96 \mathrm{~h}$ after induction of luteolysis. Estrus was synchronized using an intramuscular injection of GnRH $(100 \mu \mathrm{g})$ and induction of luteolysis using $\mathrm{PGF}_{2 \alpha}(25 \mathrm{mg}) 7 \mathrm{~d}$ later.

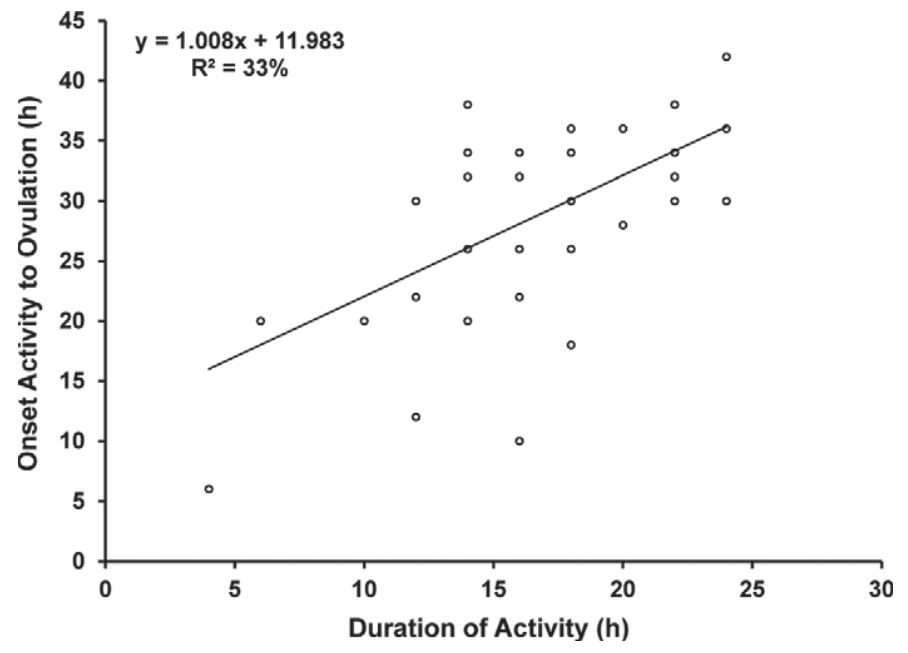

Figure 6. Relationship between duration of activity and the interval from onset of activity to ovulation for cows $(\mathrm{n}=38)$ detected in estrus by the accelerometer system (Heatime; SCR Engineers Ltd., Netanya, Israel) within $96 \mathrm{~h}$ after induction of luteolysis (experiment 1). Estrus was synchronized using an intramuscular injection of $\mathrm{GnRH}$ $(100 \mu \mathrm{g})$ and induction of luteolysis using $\mathrm{PGF}_{2 \alpha}(25 \mathrm{mg}) 7 \mathrm{~d}$ later.

LH surge from the pituitary gland. In agreement with this idea, Bloch et al. (2006) observed that most of the variation in the estrus-to-ovulation interval in lactating dairy cows could be explained by the variation in the onset of estrus-to-LH-surge interval. Indeed, in cows with a very long estrus-to-ovulation interval ( $>36 \mathrm{~h})$, the time from the onset of estrus to the LH surge was $9 \mathrm{~h}$ compared with $<4 \mathrm{~h}$ for cows with normal estrusto-ovulation intervals (Bloch et al., 2006). Interestingly, Bloch et al. (2006) also reported that cows with a very long estrus-to-ovulation interval had less estradiol during the follicular phase despite a similar size of the dominant follicle than cows with normal estrus-to-ovulation intervals. The low estradiol concentration could result from increased hepatic metabolism of steroids associated with high feed intake of lactating dairy cows (Sangsritavong et al., 2002) and could explain the uncoupling between the onset of estrus and the LH surge.

A negative linear association between milk production during the $7 \mathrm{~d}$ preceding estrus activity and peak intensity for weighted activity $\left(P=0.01 ; \mathrm{R}^{2}=16 \%\right)$ was observed. As milk production near the time of estrus increased, peak intensity of weighted activity decreased (Figure 7). In agreement with these data, López-Gatius et al. (2005b) reported a negative linear association between milk production and walking activity during estrus. Although estradiol concentrations were not measured in our experiment, we speculate that this negative association between milk production and estrus intensity could be explained, at least 
7124

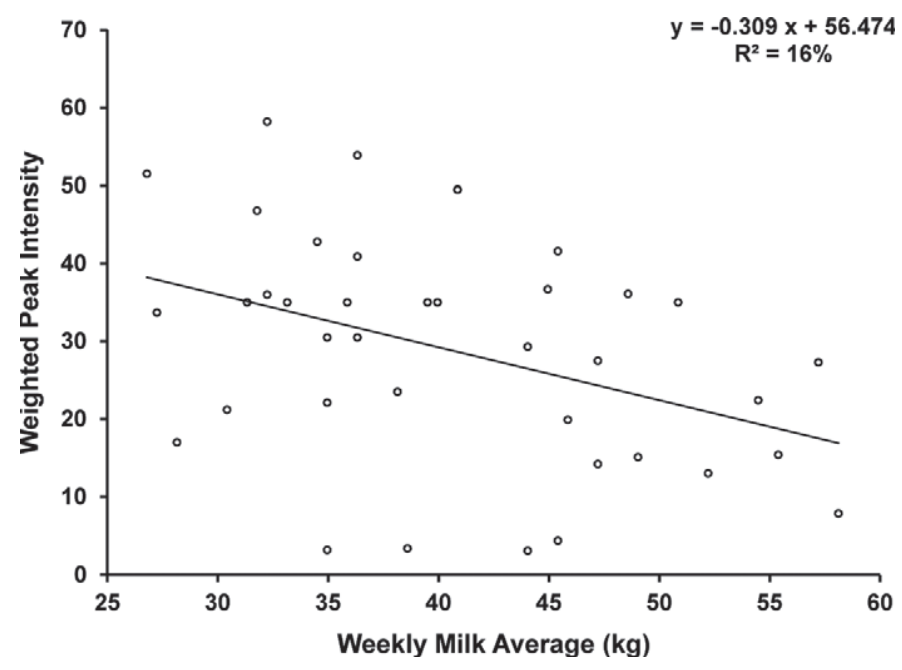

Figure 7. Relationship between milk production and weighted peak intensity recorded by the accelerometer system (Heatime; SCR Engineers Ltd., Netanya, Israel; experiment 1). Milk production was calculated as the mean daily production during the 7-d period preceding estrus activity but not including the day of estrus. Estrus was synchronized using an intramuscular injection of $\mathrm{GnRH}(100 \mu \mathrm{g})$ and induction of luteolysis using $\mathrm{PGF}_{2 \alpha}(25 \mathrm{mg}) 7 \mathrm{~d}$ later.

in part, by decreased estradiol during the follicular phase (Wiltbank et al., 2006) due to hepatic steroid metabolism (Sangsritavong et al., 2002). Indeed, positive correlations between estrous behavior scores and estradiol concentrations near the time of estrus have been reported for lactating dairy cows (Lyimo et al., 2000; Roelofs et al., 2004). Further research is needed to clarify the relationship between estrus expression and milk production in dairy cows.

\section{Experiment 2-Fertility of Cows Receiving GnRH at Al After Detection of Estrus Based on the Accelerometer System}

Our hypothesis for experiment 2 was that treatment with GnRH at the time of AI would increase fertility compared with untreated cows. In the present experiment, however, $\mathrm{P} / \mathrm{AI}$ did not differ $(P=0.40)$ for GnRH $(26.2 \%, 140 / 534)$ compared with control $(22.7 \%$, $101 / 445)$ cows at $35 \pm 3$ or $65 \pm 3 \mathrm{~d}[21.8 \%,(97 / 445)$ vs. $24.9 \%$, (133/354) respectively; $P=0.48]$ after AI. Our hypothesis was partially based on results from Morgan and Lean (1993) who conducted a meta-analysis of 40 experiments described in 27 published papers and concluded that treatment with $\mathrm{GnRH}$ or $\mathrm{GnRH}$ analogs at insemination increased the overall risk of pregnancy by $12.5 \%$ in treated cows. Treatment of cows and heifers $72 \mathrm{~h}$ after the second of 2 sequential injections of $\mathrm{PGF}_{2 \alpha}$ increased conception rate compared with saline-treated controls and induced a preovulatory LH surge in some of the cattle, but also decreased serum P4 concentrations in cattle receiving GnRH (Lucy and Stevenson, 1986). One physiologic mechanism by which GnRH treatment at AI could increase fertility is by inducing cows to ovulate that would otherwise fail to ovulate after a spontaneous estrus. Indeed, $5 \%$ of synchronized cows in experiment 1 failed to ovulate after estrus (detected with the accelerometer system), a similar rate of ovulation failure reported by López-Gatius et al. (2005a). If the mechanism by which GnRH increases fertility is by reducing the percentage of cows with ovulation failure, perhaps there were too few cows experiencing ovulation failure to produce a treatment effect in experiment 2 . In addition, Morgan and Lean (1993) reported that the risk of pregnancy tended to be greater when cows were treated with $\geq 250 \mu \mathrm{g}$ of $\mathrm{GnRH}$, whereas only $100 \mu \mathrm{g}$ of GnRH was administered at AI in the present experiment. Despite the increase observed in $\mathrm{GnRH}$-induced LH secretion in lactating dairy cows after doubling the dose of GnRH from 100 to $200 \mu \mathrm{g}$ (Giordano et al., 2012), we speculate that insufficient LH secretion may not have been the limitation in experiment 2 because $\mathrm{GnRH}$ was given in a low progesterone environment (during estrus) when the LH response to a $100-\mu \mathrm{g}$ dose of $\mathrm{GnRH}$ should be adequate to induce ovulation in most cows (Giordano et al., 2012).

Another potential mechanism by which treatment with GnRH at the time of AI could improve fertility of repeat breeder cows is an increase in circulating progesterone after ovulation (Mee et al., 1993). In the present study, we did not attempt to measure progesterone concentrations after AI; however, it seems unlikely that treatment with GnRH may have affected fertility through increased progesterone, as fertility was not improved by treatment with $\mathrm{GnRH}$ at any service number.

Morgan and Lean (1993) also reported that some variation in results among the studies in their metaanalysis were attributable to $\mathrm{AI}$ number at $\mathrm{GnRH}$ treatment with the increased risk of pregnancy being greatest $(22.5 \%)$ for repeat breeders, whereas the risk of pregnancy was similar for GnRH-treated cows to that of control cows at first service. In experiment 2 , however, we detected no treatment by AI service number interaction $(P=0.40)$ on $\mathrm{P} / \mathrm{AI}$ (Figure 8). Treatment of cows with GnRH at the time of AI is widely used in the dairy industry partly because it is easy and relatively inexpensive to administer GnRH to cows when they are identified and restrained for AI. It is likely, however, that treating cows with GnRH at AI is too late to have a physiologic effect on fertility. Treatment of cows and heifers $72 \mathrm{~h}$ after the second of 
2 sequential injections of $\mathrm{PGF}_{2 \alpha}$ increased conception rate compared with saline-treated controls and induced a preovulatory LH surge in some but not all cattle (Lucy and Stevenson, 1986). Treatment with a GnRH analog within $3 \mathrm{~h}$ of the onset of estrus increased conception rates by more than 14 percentage points, and the effect of treatment was greatest during the summer, in cows with low body condition at AI, and in primiparous cows (Kaim et al., 2003). Furthermore, treatment with GnRH eliminated differences in conception rate for cows inseminated early or later relative to the onset of estrus and increased conception rate in cows with postpartum reproductive disorders (Kaim et al., 2003).

Although no effect of GnRH treatment was observed in experiment 2 , a season by parity interaction $(P<$ 0.01 ) on $\mathrm{P} / \mathrm{AI}$ was observed. This interaction indicated no difference in $\mathrm{P} / \mathrm{AI}$ between parities during the cool season, but multiparous cows had fewer P/AI compared with primiparous cows during the warm season (Figure 9). We are not aware of other data that have reported such a differential effect between parities due to heat stress, and we cannot determine whether this is a physiologic effect or an effect related to this particular farm. Finally, pregnancy loss from $35 \pm 3$ to $65 \pm$ $3 \mathrm{~d}$ after TAI did not differ $(P=0.70)$ between $\mathrm{GnRH}$ and untreated control cows (4.0 vs. $5.0 \%$, respectively), or between primiparous and multiparous cows (3.8 vs. $5.3 \%$, respectively; $P=0.59$ ).

\section{CONCLUSIONS}

A practical implication of the data from experiment 1 is that for lactating dairy cows under similar conditions, two-thirds of the cows that would be considered properly synchronized would be inseminated based on the accelerometer system and would ovulate after AI. The remaining cows either would not be inseminated because they are not detected in estrus or would not have a chance to conceive to AI because they would fail to ovulate after estrus. These data underscore the importance of implementing a comprehensive reproductive management program for identification and treatment of cows that would otherwise not be inseminated and to identify those cows failing to ovulate when cycling spontaneously. Based on data from the present experiment using the accelerometer system, the mean time of AI in relation to ovulation was acceptable for most of the cows detected in estrus; however, variability in the duration of estrus and timing of $\mathrm{AI}$ in relation to ovulation could lead to poor fertility in some cows. In experiment 2, treatment with $\mathrm{GnRH}$ at the time of AI after estrus determined by the accelerometer system did not affect fertility in lactating dairy cows,

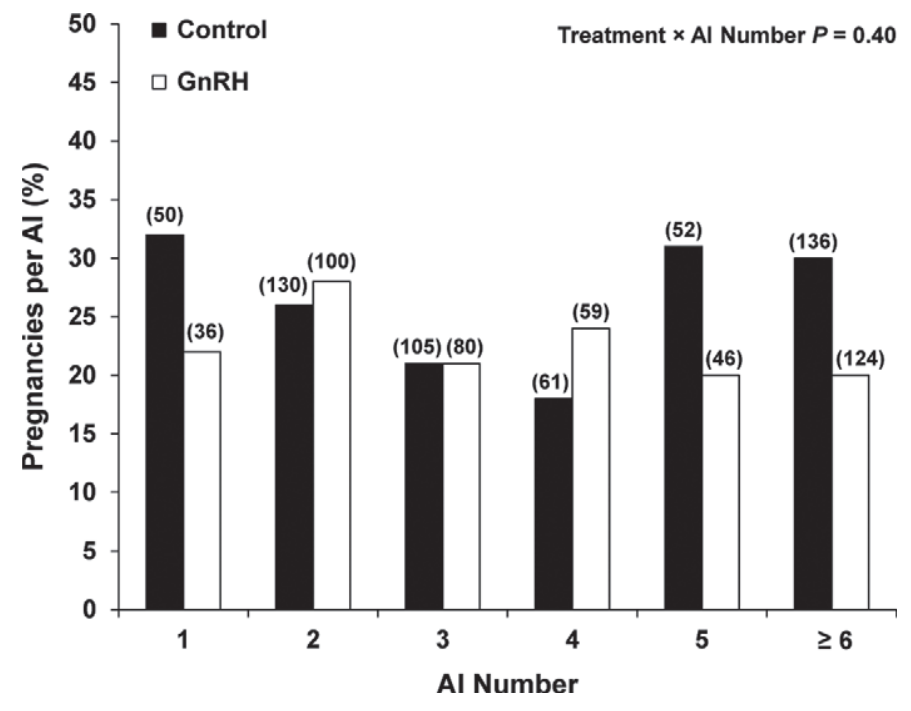

Figure 8. Effect of AI service number on pregnancies per AI for cows receiving $\mathrm{GnRH}(100 \mu \mathrm{g})$ or no treatment (control) at the time of AI after detection of estrus using an accelerometer system (Heatime; SCR Engineers Ltd., Netanya, Israel) in experiment 2. The numbers in parentheses above bars denote the number of cows in the control and $\mathrm{GnRH}$ treatments for each AI service number.

and we detected no treatment by AI service number interaction. Contrary to some previous experiments, these data do not support the use of GnRH at the time of AI after detection of estrus using an accelerometer system as a strategy to improve fertility in lactating

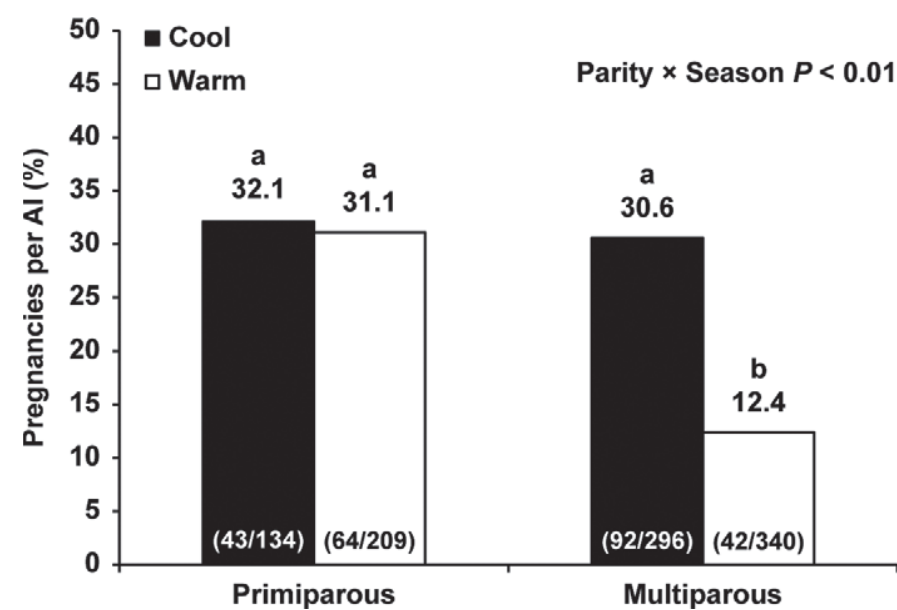

Figure 9. Pregnancies per AI for primiparous and multiparous cows inseminated after detection of estrus using an accelerometer system (Heatime; SCR Engineers Ltd., Netanya, Israel) during the cool versus the warm season of the year in experiment 2. A daily high temperature $>20^{\circ} \mathrm{C}$ on the day of $\mathrm{AI}$ was classified as having occurred during the warm season, whereas a daily high temperature $\leq 20^{\circ} \mathrm{C}$ on the day of AI was classified as having occurred during the cool season. ${ }^{\mathrm{a}, \mathrm{b}}$ Parity by season interaction $(P<0.01)$. Numbers above bars represent pregnancies per AI $(\%)$. 
dairy cows. Future experiments should investigate the effect of GnRH administration relative to the onset of activity and as determined by accelerometer systems as a potential means to improve fertility in dairy cattle.

\section{ACKNOWLEDGMENTS}

The authors thank Majestic View Dairy (Lancaster, WI) and their staff for the use of their cows and facilities for these experiments. This research was supported by Hatch project WIS01171 to P. M. Fricke.

\section{REFERENCES}

Bar, D. 2010. Optimal timing of insemination using activity collars. Page 100 in Proc. of the 1st North Am. Conf. Precision Dairy Management, Toronto, Canada. Progressive Dairy Operators, Elora, ON, Canada.

Bloch, A., Y. Folman, M. Kaim, Z. Roth, R. Braw-Tal, and D. Wolfenson. 2006. Endocrine alterations associated with extended time interval between estrus and ovulation in high-yield dairy cows. J. Dairy Sci. 89:4694-4702.

Caraviello, D. Z., K. A. Weigel, P. M. Fricke, M. C. Wiltbank, M. J. Florent, N. B. Cook, K. V. Nordlund, N. R. Zwald, and C. L. Rawson. 2006. Survey of management practices on reproductive performance of dairy cattle on large US commercial farms. J. Dairy Sci. 89:4723-4735.

Chebel, R. C., and J. E. Santos. 2010. Effect of inseminating cows in estrus following a presynchronization protocol on reproductive and lactation performances. J. Dairy Sci. 93:4632-4643.

Dransfield, M. B., R. L. Nebel, R. E. Pearson, and L. D. Warnick. 1998. Timing of insemination for dairy cows identified in estrus by a radiotelemetric estrus detection system. J. Dairy Sci. 81:18741882.

Giordano, J. O., J. N. Guenther, G. Lopes Jr., M. M. Herlihy, A. B Nascimento, P. M. Fricke, and M. C. Wiltbank. 2012. Effect of progesterone on magnitude of the luteinizing hormone surge induced by two different doses of gonadotropin-releasing hormone in lactating dairy cows. J. Dairy Sci. 95:3781-3793.

Gwazdauskas, F. C., R. L. Nebel, D. J. Sprecher, W. D. Whittier, and M. L. McGilliard. 1990. Effectiveness of rump-mounted devices and androgenized females for detection of estrus in dairy cattle. J. Dairy Sci. 73:2965-2970.

Hawk, H. W. 1987. Transport and fate of spermatozoa after insemination of cattle. J. Dairy Sci. 70:1487-1503.

Holman, A., J. Thompson, J. E. Routly, J. Cameron, D. N. Jones, D. Grove-White, R. F. Smith, and H. Dobson. 2011. Comparison of oestrus detection methods in dairy cattle. Vet. Rec. 169:47.

Hunter, R. H. F. 2003. The process of ovulation and shedding of an oocyte. Pages 262-286 in Physiology of the Graafian Follicle and Ovulation. Cambridge University Press, Cambridge, UK.

Hunter, R. H. F., and I. Wilmut. 1983. The rate of functional sperm transport into the oviducts of mated cows. Anim. Reprod. Sci. 5:167-173.

Jónsson, R., M. Blanke, N. K. Poulsen, F. Caponetti, and S. Højsgaard. 2011. Oestrus detection in dairy cows from activity and lying data using on-line individual models. Comput. Electron. Agric. 76:6-15.

Kaim, M., A. Bloch, D. Wolfenson, R. Braw-Tal, M. Rosenberg, H. Voet, and Y. Folman. 2003. Effects of GnRH administered to cows at the onset of estrus on timing of ovulation, endocrine responses, and conception. J. Dairy Sci. 86:2012-2021.

Kiddy, C. A. 1977. Variation in physical activity as an indication of estrus in dairy cows. J. Dairy Sci. 60:235-243.
Lopez, H., L. D. Satter, and M. C. Wiltbank. 2004. Relationship between level of milk production and estrous behavior of lactating dairy cows. Anim. Reprod. Sci. 81:209-223.

López-Gatius, F., M. López-Béjar, M. Fenech, and R. H. F. Hunter. 2005a. Ovulation failure and double ovulation in dairy cattle: Risk factors and effects. Theriogenology 63:1298-1307.

López-Gatius, F., P. Santolaria, I. Mundet, and J. L. Yániz. 2005b. Walking activity at estrus and subsequent fertility in dairy cows. Theriogenology 63:1419-1429.

Lucy, M. C., and J. S. Stevenson. 1986. Gonadotropin-releasing hormone at estrus: Luteinizing hormone, estradiol, and progesterone during the periestrual and postinsemination periods in dairy cattle. Biol. Reprod. 35:300-311.

Lyimo, Z. C., M. Nielen, W. Ouweltjes, T. A. Kruip, and F. J. van Eerdenburg. 2000. Relationship among estradiol, cortisol and intensity of estrous behavior in dairy cattle. Theriogenology 53:17831795.

Maatje, K., S. H. Loeffler, and B. Engel. 1997. Predicting optimal time of insemination in cows that show visual signs of estrus by estimating onset of estrus with pedometers. J. Dairy Sci. 80:1098-1105.

Mee, M. O., J. S. Stevenson, B. M. Alexander, and R. G. Sasser. 1993. Administration of GnRH at estrus influences pregnancy rates, serum concentrations of LH, FSH, estradiol-17 $\beta$, pregnancy-specific protein B, and progesterone, proportion of luteal cell types, and in vitro production of progesterone in dairy cows. J. Anim. Sci. 71:185-198.

Miller, R. H., H. D. Norman, M. T. Kuhn, J. S. Clay, and J. L. Hutchison. 2007. Voluntary waiting period and adoption of synchronized breeding in dairy herd improvement herds. J. Dairy Sci. 90:1594-1606

Morgan, W. F., and I. J. Lean. 1993. Gonadotrophin-releasing hormone treatment in cattle: A meta-analysis of the effects on conception at the time of insemination. Aust. Vet. J. 70:205-209.

NRC. 2001. Nutrient Requirements of Dairy Cattle. 7th ed. Natl. Acad. Sci., Washington, DC.

Palmer, M. A., G. Olmos, L. A. Boyle, and J. F. Mee. 2010. Estrus detection and estrus characteristics in housed and pastured HolsteinFriesian cows. Theriogenology 74:255-264.

Peralta, O. A., R. E. Pearson, and R. L. Nebel. 2005. Comparison of three estrus detection systems during summer in a large commercial dairy herd. Anim. Reprod. Sci. 87:59-72.

Ranasinghe, R. M., T. Nakao, K. Yamada, and K. Koike. 2010. Silent ovulation, based on walking activity and milk progesterone concentrations, in Holstein cows housed in a free-stall barn. Theriogenology 73:942-949.

Roelofs, J. B., E. G. Bouwman, S. J. Dieleman, F. J. Van Eerdenburg, L. M. Kaal-Lansbergen, N. M. Soede, and B. Kemp. 2004. Influence of repeated rectal ultrasound examinations on hormone profiles and behaviour around oestrus and ovulation in dairy cattle. Theriogenology 62:1337-1352.

Roelofs, J. B., E. A. M. Graat, E. Mullaart, N. M. Soede, W. Voskamp-Harkema, and B. Kemp. 2006. Effects of insemination-ovulation interval on fertilization rates and embryo characteristics in dairy cattle. Theriogenology 66:2173-2181.

Roelofs, J. B., F. J. van Eerdenburg, N. M. Soede, and B. Kemp. 2005. Pedometer readings for estrous detection and as predictor for time of ovulation in dairy cattle. Theriogenology 64:1690-1703.

Sangsritavong, S., D. K. Combs, R. Sartori, L. E. Armentano, and M. C. Wiltbank. 2002. High feed intake increases liver blood flow and metabolism of progesterone and estradiol-17 $\beta$ in dairy cattle. J. Dairy Sci. 85:2831-2842.

Sartori, R., J. M. Haughian, R. D. Shaver, G. J. Rosa, and M. C. Wiltbank. 2004. Comparison of ovarian function and circulating steroids in estrous cycles of Holstein heifers and lactating cows. J. Dairy Sci. 87:905-920.

Senger, P. L. 1994. The estrus detection problem: New concepts, technologies, and possibilities. J. Dairy Sci. 77:2745-2753.

Stevenson, J. S., and E. P. Call. 1983. Influence of early estrus, ovulation, and insemination on fertility in postpartum Holstein cows. Theriogenology 19:367-375. 
Stevenson, J. S., Y. Kobayashi, and K. E. Thompson. 1999. Reproductive performance of dairy cows in various programmed breeding systems including OvSynch and combinations of gonadotropin-releasing hormone and prostaglandin $\mathrm{F}_{2 \alpha}$. J. Dairy Sci. 82:506-515.

Sveberg, G., A. O. Refsdal, H. W. Erhard, E. Kommisrud, M. Aldrin, I. F. Tvete, F. Buckley, A. Waldmann, and E. Ropstad. 2011. Behavior of lactating Holstein-Friesian cows during spontaneous cycles of estrus. J. Dairy Sci. 94:1289-1301.

Thatcher, W. W., and C. J. Wilcox. 1973. Postpartum estrus as an indicator of reproductive status in the dairy cow. J. Dairy Sci. 56:608-610.

Walker, W. L., R. L. Nebel, and M. L. McGilliard. 1996. Time of ovulation relative to mounting activity in dairy cattle. J. Dairy Sci. 79:1555-1561.
Washburn, S. P., W. J. Silvia, C. H. Brown, B. T. McDaniel, and A. J. McAllister. 2002. Trends in reproductive performance in Southeastern Holstein and Jersey DHI herds. J. Dairy Sci. 85:244-251.

Wilmut, I., and R. H. F. Hunter. 1984. Sperm transport into the oviducts of heifers mated early in oestrus. Reprod. Nutr. Dev. 24:461-468.

Wiltbank, M., H. Lopez, R. Sartori, S. Sangsritavong, and A. Gümen. 2006. Changes in reproductive physiology of lactating dairy cows due to elevated steroid metabolism. Theriogenology 65:17-29.

Xu, Z. Z., D. J. McKnight, R. Vishwanath, C. J. Pitt, and L. J. Burton. 1998. Estrus detection using radiotelemetry or visual observation and tail painting for dairy cows on pasture. J. Dairy Sci. $81: 2890-2896$ 